\title{
Caesarvi: el dios venerado en el templo del Collado de las Piedras LABRADAs (JARILla, CÁCERES)
}

Caesarvs: the Worshipped God in the Shrine of the Collado de las Piedras Labradas (Jarilla, Cáceres, Spain)

JUAN CARLOS OLIVARES PEDREÑO ${ }^{1}$, JAIME RÍO-MIRANDA ALCÓN²

(1) Área de Historia Antigua. Universitat d'Alacant. jcolivares@ua.es

(2) Grupo Cultural de Valdeobispo. caparra@caparra.es

RESUMEN:

En el presente artículo estudiamos algunas inscripciones votivas halladas junto a las ruinas del templo romano del Collado de las Piedras Labradas (Jarilla, Cáceres). Hasta el momento, no se conocía el nombre de la deidad venerada en este recinto sagrado pero, a partir del estudio de dos de las inscripciones que de allí proceden, hemos podido concluir que el dios adorado en este templo era Caesarus, una deidad indígena lusitana. A partir de esta identificación hemos investigado el significado del teónimo y de su único posible paralelo: Caesariciaecus, testimoniado en el pueblo de Martiago (Salamanca). Teniendo en cuenta estos datos y el contexto montañoso en el que se situaba el templo, hemos propuesto que Caesarus era un dios de carácter estelar vinculado también al Más Allá.

Palabras clave: Imperio romano, templos, dioses, celtas, religión, aras votivas.

\section{Abstract:}

In this paper, we study some votive inscriptions that were found next to the ruins of the roman shrine of the Collado de las Piedras Labradas (Jarilla, Cáceres). So far, the name of the deity worshipped in this temple was not known. Nevertheless, we have concluded from the study of two inscriptions found near the temple, that the name of the worshipped god in the shrine was Caesarus, a lusitanian deity. From this identification, we have investigated the meaning of the theonym and its possible parallel: Caesariciaecus, known from an altar founded in the town of Martiago (Salamanca). Taking into account these data and the mountainous context in which the temple was located, we have proposed that Caesarus was a god of a stellar character, also linked to the afterlife.

Key words: Roman Empire, temples, gods, Celts, religion, votive altars. 
En los últimos tiempos han aparecido algunas publicaciones en las que se ha hecho referencia al templo del Collado de las Piedras Labradas y a los altares votivos que se encuentran en los alrededores del mismo sin que, hasta el momento, haya podido descifrarse el nombre de la divinidad bajo cuya advocación estaba el citado templo. Recientemente, a partir del estudio de una inscripción que se encuentra en el Museo Sayans de Casas del Castañar (Cáceres), pero que procede del Collado de las Piedras Labradas, hemos podido llevar a cabo una propuesta de desciframiento del nombre de la deidad venerada en el templo que, a nuestro juicio, es plenamente solvente ${ }^{1}$.

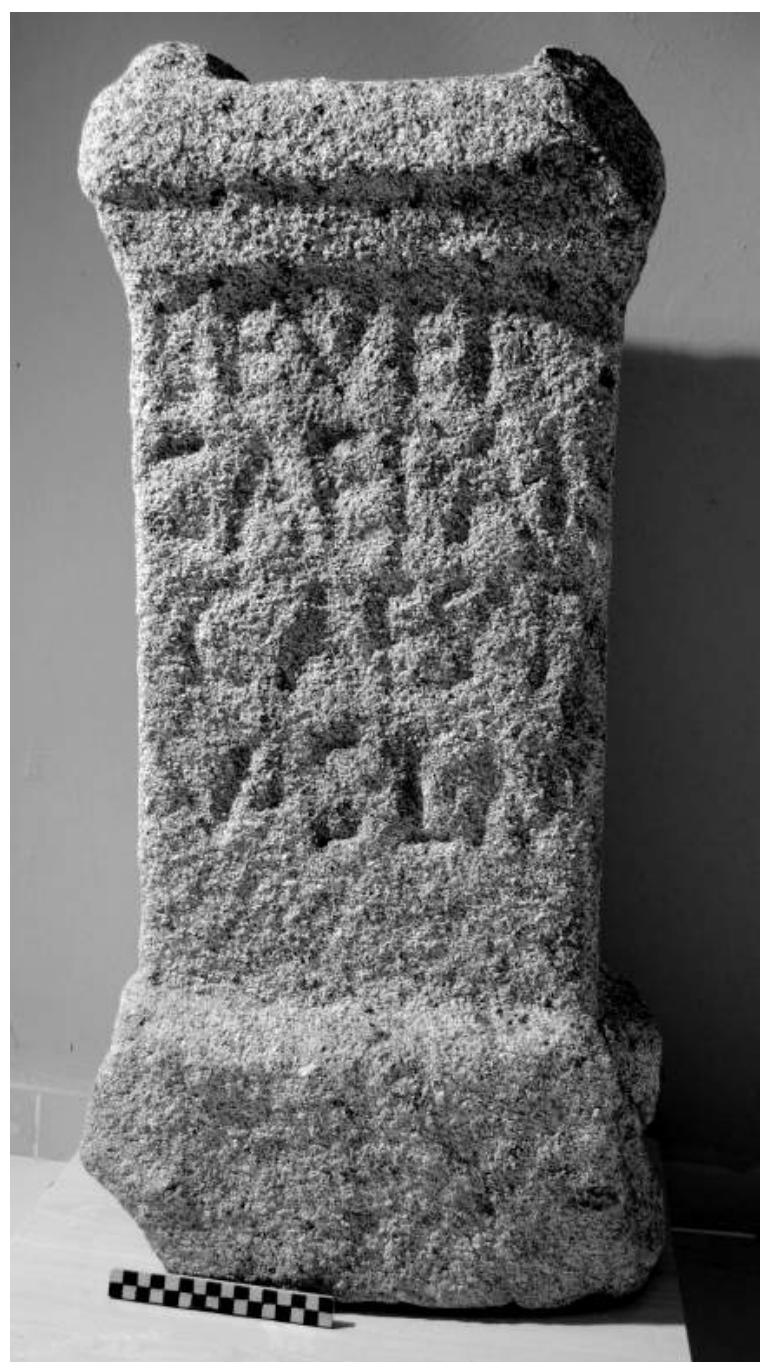

Fig. 1: Ara votiva conservada en el Museo Sayans, de Casas del Castañar (foto: J. C. Olivares).
La pieza que nos permitió plantear la hipótesis de trabajo se había encontrado medio enterrada en la falda sur del Collado de las Piedras Labradas, en las cercanías del templo, junto a cinco aras más. Esta inscripción se interpretó de diferentes maneras a partir de una lectura incompleta del texto (fig. 1). Recientemente, pudimos comprobar que en la línea 3 no aparecían únicamente cuatro letras que se leían como CAES, sino que se veían dos letras más que completaban el texto hasta el final del campo epigráfico: CAESAR. Dado que la primera línea reflejaba el cognomen Severus y que la segunda mostraba otro cognomen en genitivo, Caepai, testimoniado también en otra inscripción de cercana procedencia (GómezPantoja 2013: 280-283), sólo cabía interpretar la tercera línea como la referencia al teónimo Caesar(---). Esta interpretación podía llevar a cierta confusión, puesto que podía referirse a antropónimos conocidos en Hispania o, incluso, al cognomen del dictador romano.

En una reciente publicación, la inscripción fue interpretada dejando sin resolver totalmente el final del teónimo (Olivares 2017: 181-183):

\section{Sever(us) / Caepai (filius) / Caesar(---) / v(otum) . $s($ olvit $) \cdot l($ ibens $) \cdot a($ nimo $) \cdot$}

A partir de esta nueva lectura, nos propusimos llevar a cabo una revisión del resto de aras votivas que habían sido halladas en el Collado de las Piedras Labradas, con la intención de resolver el enigma del teónimo venerado en el templo.

En este sentido, analizamos primero un ara en granito procedente de las ruinas del recinto (fig. 2), que ya había sido estudiada por varios investigadores (vid.infra).

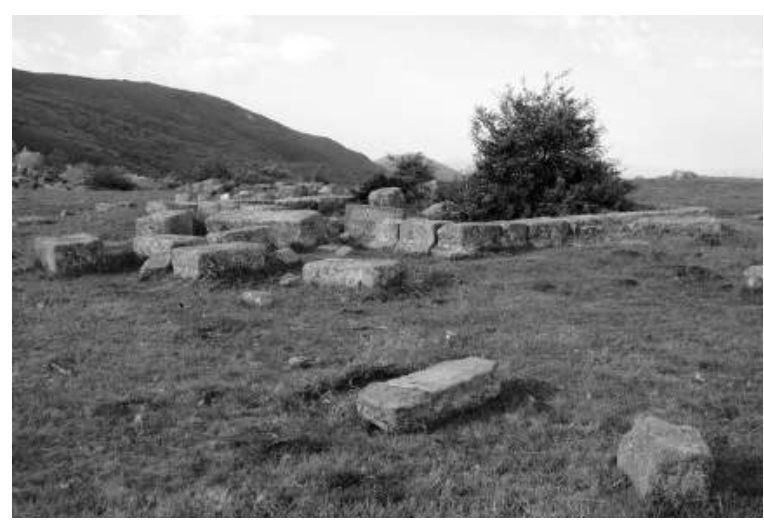

Fig. 2: Restos del templo con la ofrenda a Caesarus en primer plano (foto: Olivares y Río-Miranda). 
Se trata de un altar en granito cuyo zócalo está muy desgastado, quedando el saliente por su parte frontal y por su lado derecho (figs. 3 y 4). Su cabecera ha perdido los ángulos derecho e izquierdo, pero quedan rastros de su moldura frontal, con incisiones horizontales y paralelas que dejan bandas levemente resaltadas. Las medidas máximas de la pieza son 86,5 x 35 cm y su campo epigráfico mide 57 x $32 \mathrm{~cm}$. Las letras son capitales rústicas con

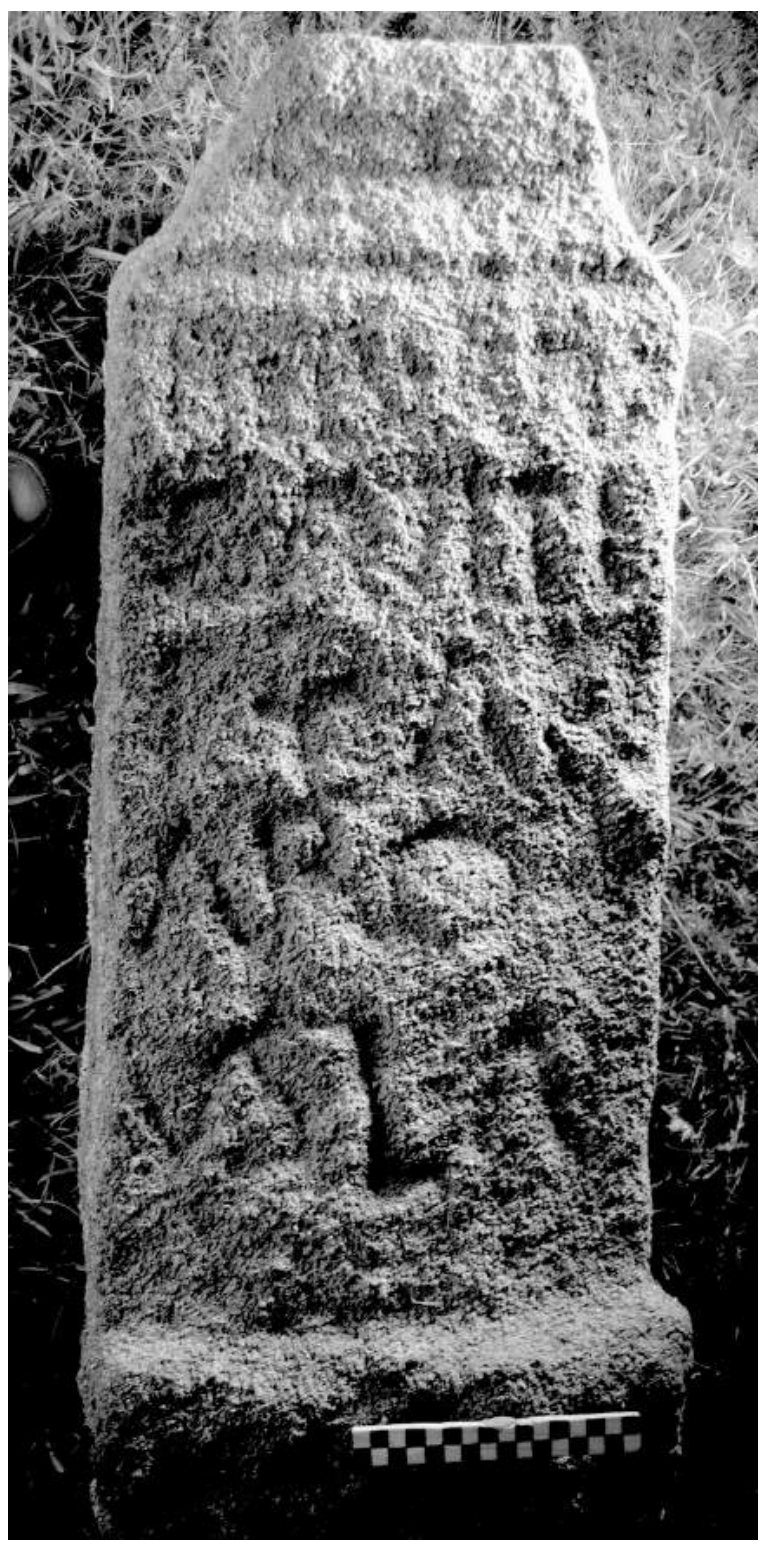

Fig. 3: Foto con luz desde el lado derecho del ara del Collado de las Piedras Labradas, de Jarilla, Cáceres (foto: J. C. Olivares y J. Río-Miranda). deficiente alineación y muy irregulares en tamaño y forma. En cuanto a las interpunciones, el desgaste de toda la superficie inscrita tiene como consecuencia que sólo se pueda ver con cierta claridad una en la tercera línea, aunque también en la quinta se perciben, muy levemente, puntos.

El estudio pormenorizado de la pieza sobre el terreno nos llevó a cambiar las interpretaciones realizadas hasta

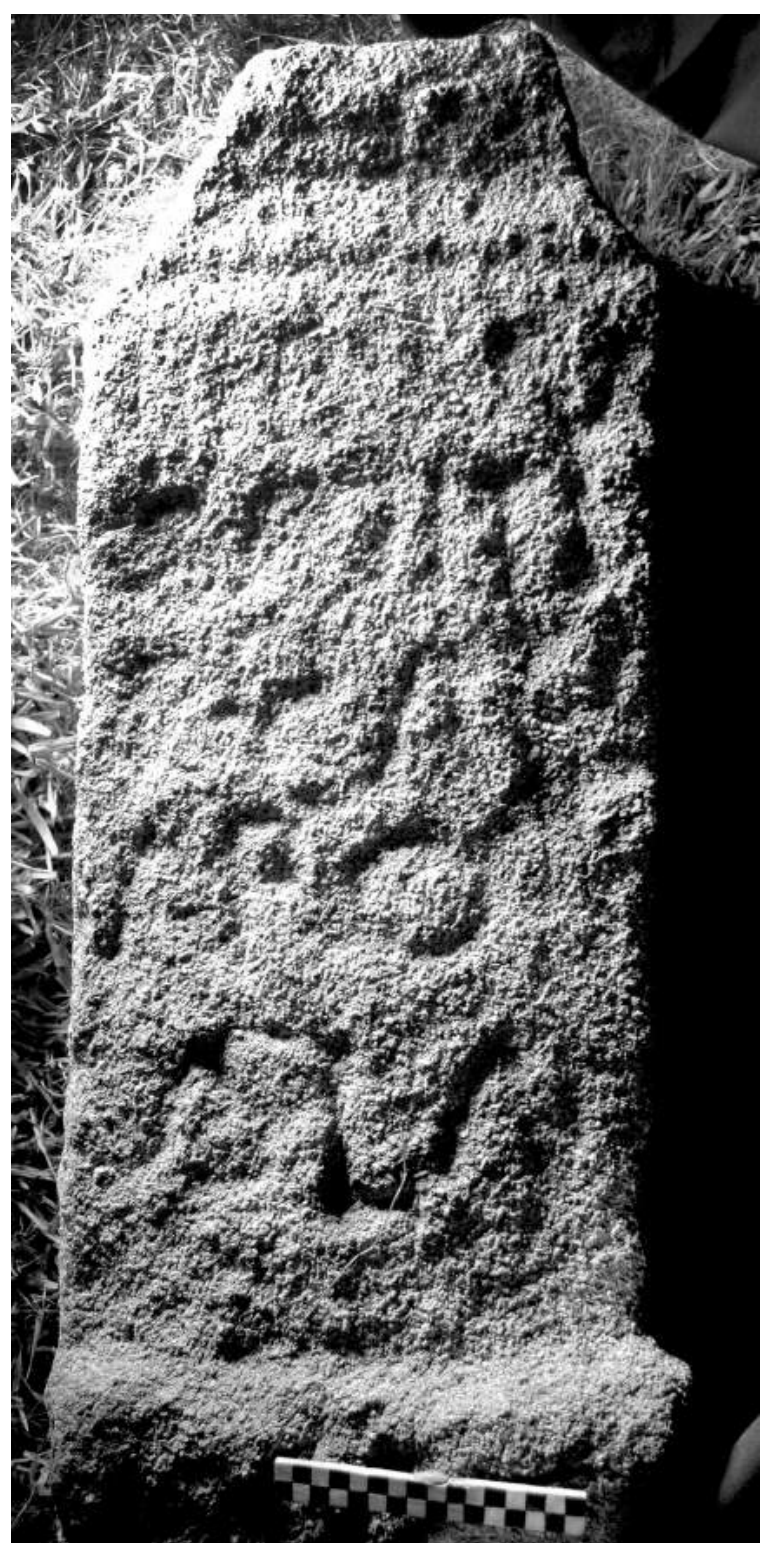

Fig. 4: Vista con luz desde el lado izquierdo de la misma ara del Collado de las Piedras Labradas, de Jarilla (foto: J. C. Olivares y J. Río-Miranda). 
la fecha, resolviéndola y dando pleno sentido a su lectura, que era absolutamente coherente con la de la pieza, conservada en el Museo Sayans, que vimos arriba. Nuestra lectura es:

\section{Reburru/s $\cdot$ Aviti / f(ilius) $\cdot$ Caes/aro / v(otum) s(olvit) l(ibens) a(nimo)}

Sayans, 1957, 215, no 4, 1. 1-4: MEB[...] / [..]VIES / P[.][E]CA[.] / AP[R]O[.] (HAE 1787); Hurtado, 1977, 343, no 808; Alvarado, García-Hoz y González, 1998, 8, $\mathrm{n}^{\circ}$ 2; Río-Miranda e Iglesias, 2007, 2, $\mathrm{n}^{\mathrm{o}} 3$, foto: $I[+]$ $s[++] n[+] /$ su[+]niti / P Cap / Aro / v(otum) s(olvit) l(ibens) m(erito); Esteban, 2013, 74, no 982, 1. 1-4: [-----] / [------] / P CA[---] / ARO[---].

Dado que la terminación del nombre de la deidad estaba clara en esta pieza, esta conclusión nos llevó a resolver el final del teónimo en la inscripción anterior, concluyendo que el nombre del dios que se veneraba en el templo del Collado de las Piedras Labradas era Caesaro (dat.). La lectura de la pieza expuesta en el Museo Sayans debería ser, por tanto, la siguiente (fig. 1):

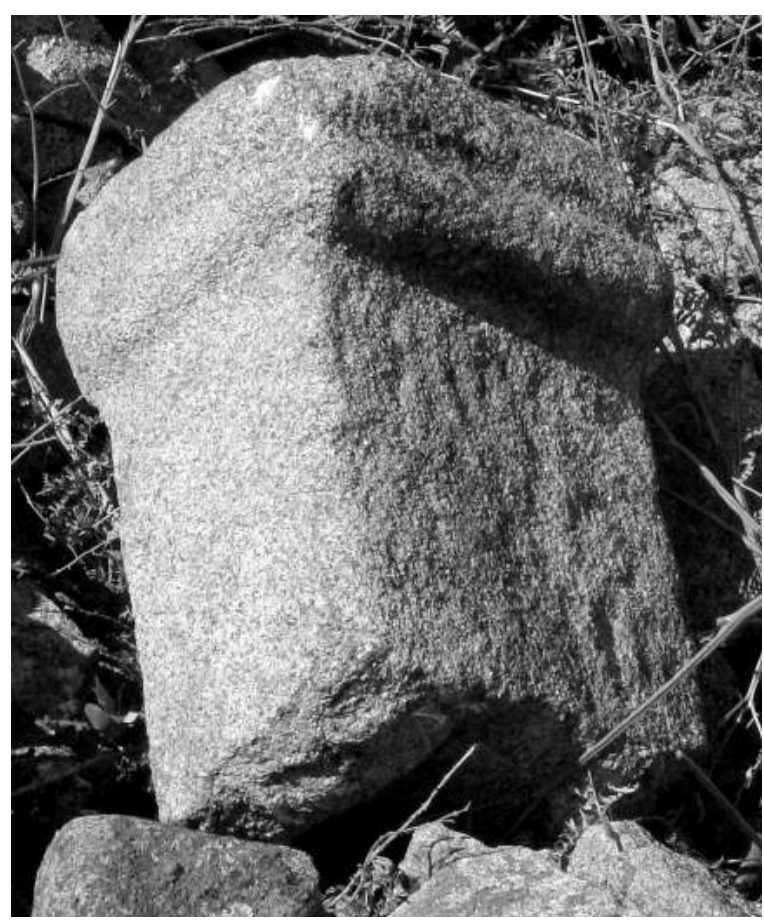

Fig. 5: Fragmento de altar en las cercanías del templo (foto: J. RíoMiranda y M. A. Iglesias).
Sever(us) / Caepai (filius) / Caesar(o) / v(otum) . s(olvit) $\cdot$ l(ibens $) \cdot a($ nimo $)$

En el Collado de las Piedras Labradas había otros monumentos votivos, como la parte superior de un ara en granito que había perdido su base y parte del fuste. Cuando subimos recientemente al cerro donde está el templo, estuvimos buscando la pieza y no pudimos encontrarla, debido al gran crecimiento de los matorrales que se había dado en torno a una pequeña construcción, en la que había estado hacía pocos años este fragmento de altar. No obstante, disponemos de una foto que realizaron RíoMiranda e Iglesias, de la que se puede obtener una probable lectura (fig. 5).

$$
[++] \cdot \text { Ca[e]s/aro / [------] / ------ }
$$

Río-Miranda e Iglesias, 2007, 2, foto, 1. 1: I[++]ins / Aro / v(otum) s(olvit) $[++]$.

Desgraciadamente, la lectura no puede ser comprobada, por el momento, con la autopsia de la pieza, lo que podría haber supuesto una confirmación añadida a nuestra hipótesis, aunque la foto disponible de la pieza apunta, con cierta fiabilidad, a que se trata de otra referencia al teónimo Caesarus. Sin embargo, son dudosas dos letras al comienzo de la inscripción, que podrían constituir las abreviaturas de Deus Sanctus. Finalmente, también nos falta el nombre del oferente y la fórmula votiva aunque, dado que la pieza está fragmentada por la mitad, cabe suponer que alguno de estos elementos se hizo constar en la última línea visible y en la parte perdida. También está muy desgastada la letra E del posible teónimo. Por tanto, proponemos, aunque con todas las reservas derivadas del hecho de que no pudimos estudiar la pieza sobre el terreno, que Caesarus debería, también, la deidad citada en la misma.

En el entorno del templo, se halló un cuarto monumento con inscripción, que era un ara votiva con zócalo y cabecera y de la que también hay una fotografía disponible, pero no se aprecian los caracteres en la misma. Intentamos encontrar esta pieza también entre los zarzales de la citada construcción que había a unos 150 metros del templo, pero nos fue imposible localizarla. La lectura que había sido ofrecida en su día también tiene elementos que podrían apuntar al mismo teónimo que nos ocupa: IFCIN+ / VSO++ / ARO / v(otum) s(olvit) a(nimo) l(ibens) (Río-Miranda e Iglesias 2007: 1). 
Finalmente, hemos de citar otra pieza que vio Sayans un poco alejada del recinto templario y que, en una de sus caras, tenía una inscripción en dos líneas trazadas en el sentido más largo del monumento: CECPR . SP / -----(Sayans 1957). Dado que tampoco pudimos encontrar esta pieza y no disponemos de una fotografía de calidad de la misma, no podemos proponer una lectura alternativa.

El nombre Caesarus derivaría, probablemente, de una raíz i.e. *Kais- que significaría "pelo", y se relacionaría con el a.i. Kèsara "cabellera", el lat. caesariēs "melena" o el av. gaesa- "pelo rizado" (Pokorny 1959, II: 520; Búa 2000:107; Mallory y Adams 1997: 251-252; Moussy y Bureau 1998: 15-30; De Vaan 2008: 81-82; Salinas 2013: 19). La Historia Augusta menciona también esta posibilidad, aludiendo a que César pudo recibir su nombre porque nació con una larga cabellera (Spart., Ael., 2, 3). Otros autores, como Palomar o Albertos, lo relacionaban con la raíz de gaesum "dardo de hierro" (Palomar 1957: 56; Albertos 1966: 70) o gaesi "hombres valerosos", aunque ello es menos probable (Prósper 2002: 345-346; Salinas 2013: 19; Del Hoyo 1994: 56). Solá proponía una procedencia del púnico KYSR "elefante" (Solá 1967: 310-311; Salinas 2013: 19). En este sentido, en la Historia Augusta (Spart., Ael., 2, 3), se afirmaba que, según diversos autores, el primer romano al que se llamó Caesar había recibido el nombre por haber matado un elefante, animal que en lengua mauritana se denominaba caesai (Serv., Aen., 1, 286). Ello habría sido utilizado por el dictador (Purpura 2015: passim), puesto que este animal se representa en algunas monedas del 4948 a.C., con el cognomen Caesar en el exergo (Crawford $1974,461, n^{\circ} 443,1$ ), aunque algunos autores no consideran fiable esta vinculación entre el elefante y el citado cognomen (Alföldy 1968: 9-18; Crawford 1974: 735, n. 2; Linderski 1996: 173). Según la Historia Augusta, algunas alternativas al origen del nombre tenían que ver también con "cortar", teniendo en cuenta que el primer romano llamado Caesar había nacido después de que se realizara una cesárea a su madre (Spart., Ael, 2-3; Plin., nat, 7,47$)$, aunque esta hipótesis también es poco probable (Purpura 2015: 228-229) o, finalmente, con el hecho de que sus ojos fueran de color azul celeste (Spart., Ael., 2, 3; Serv., Aen., 1, 286; De Vaan 2008: 82).

En cualquier caso, el nombre Caesarus es típicamente céltico (Albertos 1966: 70; Vallejo 2005: 245), aunque hayan formas con esa raíz que son nomina o cognomina latinos, como Caesius, Caesilius o Caesenius, Caesulla, Caesiola, Caesianus o Caeserius (Vallejo ibid. loc.cit.).

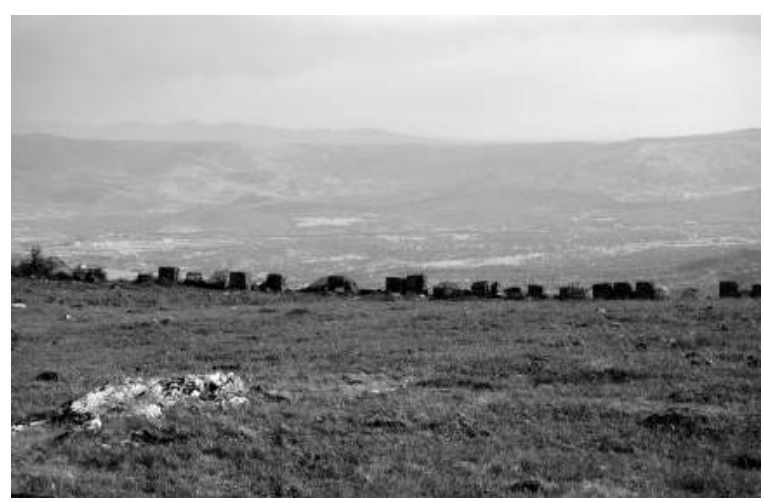

Fig. 6: Vista de sillares procedentes del templo, con el valle del Ambroz al fondo (foto: Olivares y Río-Miranda).

Por tanto, no es extraño que el caudillo lusitano que entabló combates con el ejército romano comandado por Mummius, resultando victorioso y paseando sus enseñas por toda Celtiberia entre los años 155 y 153 a.C. hasta que el legado romano acabó derrotándole, fuera llamado

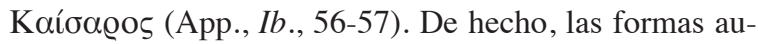
tóctonas relacionadas con Caesarus se documentan sólo en el occidente peninsular: Caesara en Medina de las Torres, Badajoz (CIL II 1031), Caisaros aparece en Paredes de Nava, Palencia (CIL II 5762), Caesarus se testimonia en Cícere, A Coruña (HAE 1695) y en Morín, Oviedo (CIL II 2698), Caesaro en Valverde de la Sierra, León (CIL II 5712) y en Oviedo (CIL II 2700), quedando el único testimonio oriental del nombre Caesaro en Tarragona, pero en un instrumento doméstico (Vallejo 2005: 244), lo que reduce la relevancia de su localización en el área mediterránea. En este sentido, Untermann resalta que estos paralelos aparecen, sobre todo, en Asturias (Untermann 1965: 81-82), como también muestra Abascal (1994: 309).

El nombre Caesarus también aparece adjetivado como teónimo o apelativo teonímico en una inscripción votiva insertada en el muro exterior de la iglesia parroquial de Martiago (Salamanca), donde consta como Caesariciaeco (vid. fig. 7) (Moreno 1992: 14-15, 1. 1-2; Del Hoyo 1994: 53-57, nº 1, lám. 1). En la cabecera de este altar aparece una incisión en forma de creciente lunar, lo que indicaría una determinada vinculación astral de la divinidad adorada (Del Hoyo 1994: 56).

Teniendo en cuenta este dato, también hemos de resaltar que el templo de Caesarus del Collado de las Piedras Labradas se encuentra a $1062 \mathrm{~m}$ de altitud, presidiendo, a lo lejos, el valle del Ambroz (fig. 6), y estaría entre los 


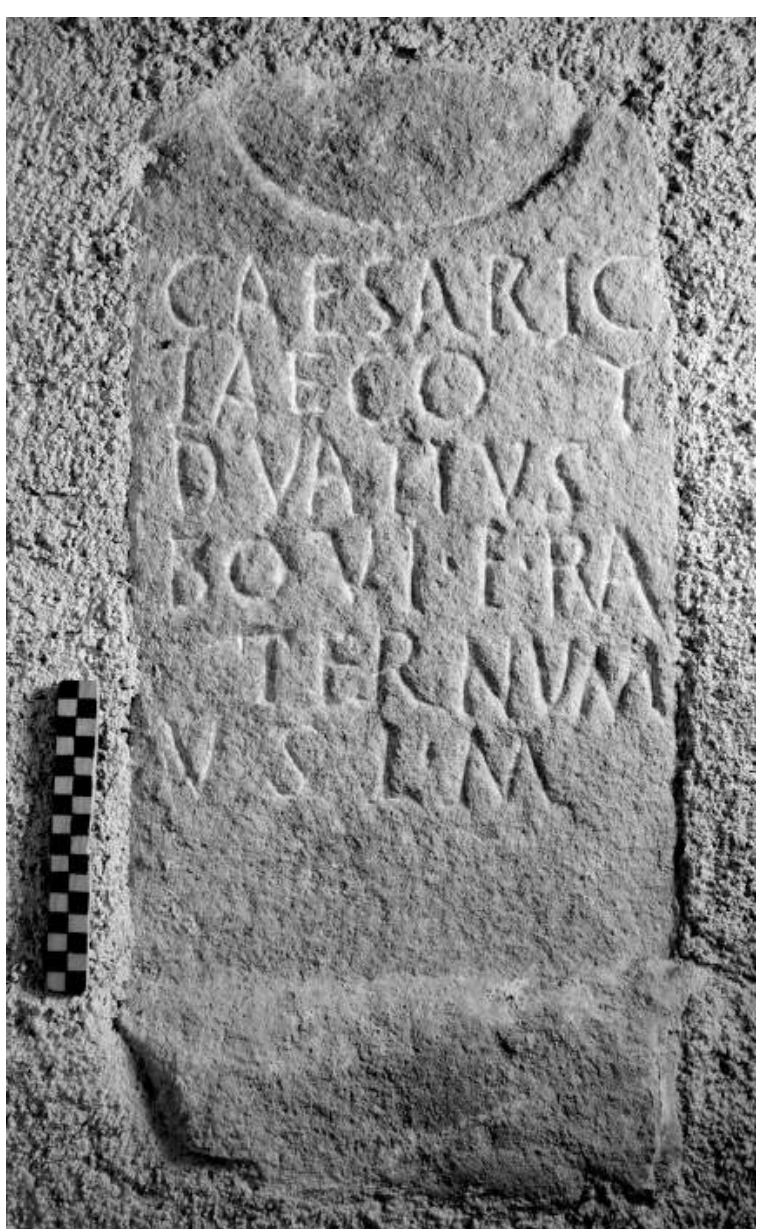

Fig. 7: Ara votiva de Martiago (Salamanca) dedicada a Caesariciaecus (foto: J. C. Olivares).

puntos más elevados de los montes de Tras la Sierra. Ello podría vincular al dios con otras divinidades indígenas cuyo culto se ha constatado en elevaciones montañosas, como Reve, del que hay testimonios en la Sierra do Larouco, situada al norte del distrito portugués de Vila-Real, y también se testimonia en el Cabeço das Fráguas (Pousafoles, Sabugal), que está situado a más de $1000 \mathrm{~m}$ de altitud (Olivares 2000: 192 ss.; 2002: 86 y 171 ss.). De igual modo, Caesarus podría tener relación, desde el punto de vista de su significación religiosa, con el dios Salama, testimoniado con seguridad en Villamiel, pueblo situado al pie del monte Jálama, cuyo nombre se relacionaría con el citado teónimo (Melena 1985: 475; Olivares 2002: 171-172).

Estos elementos iconográficos y geográficos, que son coincidentes en el culto a Caesarus o Caesariciaecus, no son extraños en el resto del territorio hispano, aunque los crecientes lunares se refieren, en cuanto a deidades indígenas, a las de género femenino. El creciente lunar aparece en la cabecera de un altar votivo dedicado a la diosa Corua, que se halló en la cima de la Serra da Marofa (Figueira de Castelo Rodrigo, Guarda), de 977 m de altura, cuando se construyó en ella la capilla de Nossa Senhora de Fátima (Curado 1985: 650-651; García 1991: 301, no 47). También tenemos ese signo astral en el frontal de la cabecera de una ofrenda votiva a la diosa Navia, que fue hallado en la corona del monte de O Picato, de San Martín de Monte de Meda (Lugo) (Arias et al. 1979: 90-92, $n^{\circ}$ 71; Ares 1976: 240), lo que llevó a Tranoy a atribuir a la diosa un rol cósmico y funerario (Tranoy 1981: 293), por el hecho de que los crecientes lunares aparecen, sobre todo, en la epigrafía funeraria (Kooy 1981: 45 ss.; Le Bohec 2014: 454 ss.).

Hemos de tener en cuenta, por otra parte, que en el altar de Marecos (Penafiel, Oporto), consta un sacrificio de animales a la diosa Nabia Corona y a Júpiter, lo que certifica la vinculación de la diosa al dios máximo de los romanos (Le Roux y Tranoy 1974: 252-255) y, además, su apelativo se asemeja en gran medida al de la diosa Corua ya citada. Es curioso, finalmente, que dos testimonios de creciente lunar asociado a deidades paleohispánicas se encontraron también en Martiago, de donde procede el altar de Caesariciaecus y que, en este caso, se vinculaba a la diosa Toga (Albertos 1952: 62) y, en Agallas, pueblo muy cercano a Martiago, donde se vincula a una deidad no citada en el altar (Del Hoyo 1994: 58-60; HEp . 5, 680). Por tanto, podrían estar vinculadas estas dos divinidades, Caesariciaecus y Toga, ya que se adoraban en el mismo lugar y aparecen con el mismo signo astral como atributo.

Si aceptamos esta vinculación entre divinidades masculinas y femeninas cuyo ámbito de actuación es el cielo, hemos de hacer constar un último altar inscrito que se halló también en el Collado de las Piedras Labradas, dedicado por Allius Agathas a una diosa cuyo nombre no se cita, puesto que sólo se menciona como Deae S(anctae) (fig. 8).

Tampoco es extraña esta relación entre las deidades estelares célticas y el creciente lunar en el territorio céltico europeo. De hecho, la intensa concentración de testimonios en distintas regiones occidentales, vinculados al ámbito funerario, indicaría un carácter céltico de este motivo iconográfico (Kooy 1981: 61). En este sentido, una ofrenda votiva al dios del cielo céltico, Taranis, hallada en Böckingen (Rheinland-Pfälz), muestra en el 
frontal de su cabecera, también, un creciente lunar (Powell 2005: 156, fig. 103; Green 2004: 221, con foto). El icono más habitual de este dios es la rueda, que se relaciona con el sol pero, como vemos, también se vincula a la luna, remarcando su carácter estelar. Lo mismo podemos concluir de algunos artefactos votivos hallados en Felmingham Hall (Norfolk), entre los que aparece el rostro de un dios con melena y barba, de cuya cabeza emergen rayos solares y que, en su parte alta, muestra un creciente lunar. Esta representación apareció junto a otros exvotos, entre los que había ruedas solares (Ross 1974: 77, fig. 22 y lám. IV; Green 1986: 46-47).

Con todo, la iconografía astral del altar de Martiago y la ubicación en altura del templo de Caesarus no son datos del todo determinantes para considerar al dios como semejante a los dioses soberanos célticos relacionados con el cielo, las montañas y los fenómenos atmosféricos, aunque los indicios apuntan, a nuestro juicio, en esta dirección.

Por otra parte, la etimología más probable de Caesarus podría tener relación, aunque no se puede asegurar, con una característica mitológica de la divinidad, la melena, lo que podría vincular a la deidad con otras divinidades célticas del continente europeo que tienen esa misma particularidad. En este sentido, podríamos citar el dios representado en un relieve circular del frontón del templo de Bath, cuyo rostro, además de bigote y barba, presenta un pelo exuberante que rodea la cara en su totalidad (Cunliffe 1984: 40-43, figs. 14, 15 y 17). Se ha debatido la posible relación con la Gorgona que aparece en el pecho de Minerva, dado que el templo de Bath se dedica a Sulis Minerva. Sin embargo, la deidad es claramente masculina y de avanzada edad. El frondoso pelo es, sin duda, la característica que más se resalta en este relieve y tendría, según Ross, una simbología solar, probablemente, en este caso también con un carácter apotropaico (Toynbee 1964: 137; Ross 1974: 120-121 y 125-126, fig. 58). También para Cunliffe se trataría de un dios solar. Del mismo modo, Green considera esta deidad acuática y solar, en consonancia con la propia deidad Sulis Minerva, cuyo nombre evoca al astro rey (Green 2004: 47). Para Hind, el sentido habría que buscarlo en la mitología clásica y estaría referido a Tifón, gigante que estaría relacionado, en este lugar, con la actividad geotermal (Hind 1996: 358-360). Por otra parte, el medallón que contiene el rostro de la probable deidad está sostenido por dos figuras femeninas aladas que parecen estar en el aire, lo que reforzaría el carácter astral de la deidad representada

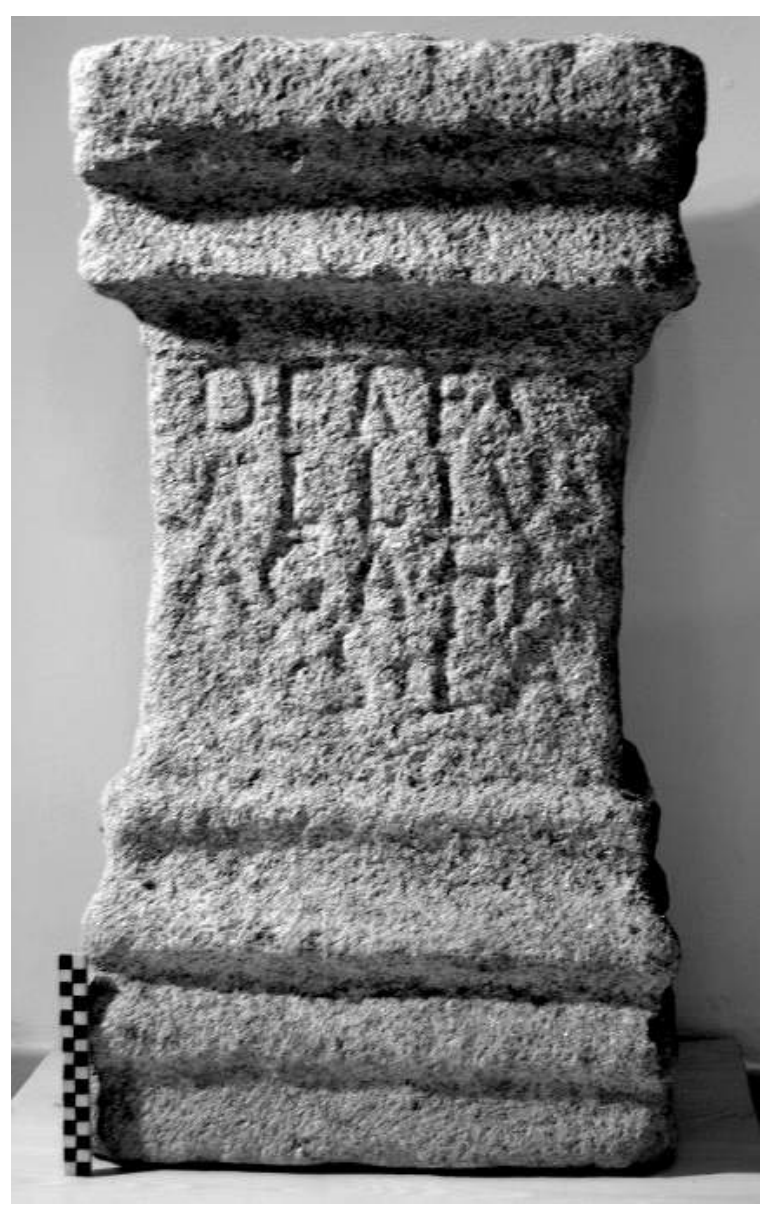

Fig. 8: Ara de Jarilla dedicada a una diosa, conservada en el Museo Sayans de Casas del Castañar (foto: J. C. Olivares).

(Cunliffe 1984: 40, fig. 14). No obstante, recientemente, esta representación se ha interpretado en el contexto de la conquista romana de Britania, como emblema de la victoria imperial, por lo que no se puede considerar fiable una vinculación de la imagen de Bath con Caesarus. En este sentido, según Cousins, la imagen se trataría de un motivo iconográfico sincrético muy utilizado en época alto-imperial en todo el mundo romano, con ejemplos en el pórtico del Foro de Augusto y en otras ciudades altamente romanizadas, en los que la imagen representaría a Júpiter Amón (Cousins 2016: 107), como en Calderousse (ibid.: 109, fig. 5) y Tarraco (ibid.: 112, fig. 9) o a dioses-río, como en Arlés (ibid.: 108, fig. 7), representando la idea del Imperio como victorioso y conquistador.

Es cierto que las divinidades célticas europeas que aparecen más habitualmente con esta característica, el pelo abundante, se relacionan con el cielo, con el sol y los 
astros, como Taranis y Sucellus, pero, en cualquier caso, la relación que podamos proponer, a partir del significado del teónimo Caesarus, con las deidades cuya melena es un elemento característico, sería muy forzada según los datos que conocemos hasta el momento.

Tampoco tenemos paralelos que indiquen que el templo pudo estar dedicado al líder lusitano Caesarus, mediante un proceso de heroización posterior a su muerte, o que el topónimo Caesarobriga se refiriera al dios del templo de Jarilla, aunque existen algunos nombres de localidades hispanas acabadas en -briga que pudieron estar referidas a deidades o héroes paleo-hispánicos, como Tongobriga, Segobriga cuya tradición se habría mantenido hasta aplicarse finalmente a generales y emperadores romanos, como Brutobriga, Augustobriga o Flaviobriga, casos que también podrían hacer pensar en una vinculación del topónimo Caesarobriga con el dictador César (Abascal 2002: 13 ss.; Almagro y Lorrio 2006-2007: 148 ss.).

Con todo, lo que podemos asegurar es el carácter autóctono del culto realizado en el Collado de las Piedras Labradas, vinculado al ámbito cultural lusitano, ya que en el entorno del lugar, las divinidades indígenas testimoniadas son también lusitanas, como Bandus o Bandua, Trebaruna, Arentius, Arentia y Quangeius. El posible paralelo Caesariciaecus aparece, sin embargo, en Martiago, en un ámbito que, sin embargo, ya se sitúa en un contexto cultural vetón. En cualquier caso, como ya hemos propuesto en varios trabajos, estamos en el límite de los ámbitos culturales lusitano y vetón por lo que, dado que las fronteras culturales nunca son del todo precisas, cabe esperar posibles localizaciones paradójicas de algunos de los testimonios (Olivares 2000-2001: passim; 2001: passim).

En definitiva, los datos disponibles nos llevan a pensar que en el templo del Collado de las Piedras Labradas se veneraba al dios lusitano Caesarus y, probablemente, a una diosa cuyo nombre desconocemos. Ambos númenes, venerados en cumbres montañosas, estarían relacionados con el cielo y los astros y ejercerían su influencia sobre las sociedades que habitaban el valle del Ambroz.

\section{NOTA}

1. El presente trabajo se enmarca en el proyecto de investigación Sociedad romana y hábito epigráfico en la Hispania Citerior (HAR2015-65168-P), otorgado por el Ministerio de Economía y Competitividad de España. Por otra parte, queremos dar las gracias a María Gabriela Iglesias Domínguez, quien nos acompañó al Collado de las Piedras Labradas, ayudándonos en el estudio del altar y en la búsqueda de otras inscripciones.

\section{BIBLIOGRAFÍA}

ABASCAL, J. M. (1994): Los nombres personales en las inscripciones latinas de Hispania, Madrid-Murcia.

ABASCAL, J. M. (2002): Téseras y monedas. Iconografía zoomorfa y formas jurídicas de la Celtiberia, Palaeohispanica 2, 9-35.

ALBERTOS, M. L. (1966): La onomástica personal primitiva de Hispania Tarraconense y Betica, Salamanca.

ALFÖLDY, A. (1968): Der Erklärung des Namens Caesar in den spätrömischen Kompendien, Bonner Historia-Augusta Colloquium 1966-1967, Bonn, 9-18.

ALMAGRO-GORBEA, M.; LORRIO, A. (2006-2007): De Sego a Augusto: los orígenes celtibéricos de Segobriga, BSAA Arqueología 72-73, 143-181.

ALVARADO, M., GARCÍA-HOZ, M. C.; GONZÁLEZ, A. (1998): El templo romano del Collado de Piedras Labradas (Jarilla, Cáceres), Homenaje a José María Blázquez (J. Mangas y J. Alvar, eds.), vol. 5, Madrid, 1-24.

BÚA, C. J. (2000): Estudio lingüístico de la teonimia lusitano gallega, Tesis Doctoral inédita, Salamanca.

COUSINS, E. H. (2016): An Imperial Image: The Bath Gorgon in Context, Britannia 47, 99-118. DOI: https:/doi.org/10.1017/S0068113X16000131

CRAWFORD, M. H. (1974): Roman Republican Coinage (2 vols.), Cambridge.

CUNLIFFE, B. (1984): Roman Bath discovered, Londres, Boston, Melbourne y Henley.

CURADO, F. P. (1985): Epigrafía das Beiras (notas e correcções -1), Beira Alta 44, 641-655.

DE VAAN, M. (2008); Etymological Dictionary of Latin and the other Italic Languages, Leiden Indo-European Etymological Dictionary Series, vol. 7 (A. Lubotsky, ed.), Leiden-Boston.

DEL HOYO, J. (1994): Nuevos teónimos en inscripciones inéditas de la provincia de Salamanca, $M C V$ 30, 53-60. DOI: https://doi.org/10.3406/casa.1994.2680

ESTEBAN, J. (2013): Corpus de inscripciones latinas de Cáceres. III. Capera, Cáceres.

GARCÍA, J. M. (1991): Religiões antigas de Portugal. Aditamentos e observações as "Religiões da Lusitania" de J. Leite de Vasconcelos, Lisboa.

GARCÍA ROZAS, R.; ABÁSOLO, J. A. (1995-2007): Algunas aportaciones al conocimiento del panteón indígena en el Occidente Peninsular, Sintria III-IV, Actas do II Colóquio Internacional de Epigrafía «Culto e Sociedade», São Miguel de Odrinhas, 165-180 [2011].

GÓMEZ-PANTOJA, J.; MADRUGA, J. V.; GONZÁLEZ CORDERO, A. (2013): Cuatro altares de La Vera, Cáceres, AEspA 86, 279-292.

DOI: https://doi.org/10.3989/aespa.086.013.016

GONZÁLEZ RODRÍGUEZ, M. C. (2001-2002): Die lateinische Epigraphie Hispaniens als Quelle für die keltische Gesellschaft und Religion, Veleia 18-19, 39-60. 
GREEN, M. J. (1986): The Gods of the Celts, Gloucester.

GREEN, M. J. (2004): Guía completa del mundo celta, Madrid.

HABA, S.; RODRIGO, V. (1986): Aportaciones a la epigrafía latina del área caparense, Norba 7, 43-60.

HIND, J. (1996): Whose Head on the Bath Temple-Pediment?, Britannia $27,358-360$.

DOI: https://doi.org/10.2307/527053

HURTADO, R. (1977): Corpus provincial de inscripciones latinas. Cáceres, Cáceres.

KOOY, C. (1981): Le croissant lunaire sur les monuments funéraires gallo-romains, Gallia 39 (1), 45-62.

DOI: https://doi.org/10.3406/galia.1981.1820

LE BOHEC, Y. (2014): Le croissant de lune chez les éduens et les lingons sous le Haut-Empire, Revue Archéologique de l'Est 63, 451-457.

LE ROUX, P.; TRANOY, A. (1974): Contribution a l'etude des regions rurales del Nor-ouest hispanique au Haut-Empire: deux inscriptions de Penafiel, III Congresso Nacional de Arqueología (vol. 1), Porto, 249-257.

LINDERSKI, J. (1996): Q. Scipio Imperator, Imperium sine fine. T. Robert S. Broughton and the Roman Republic (J. Linderski, ed.), Stuttgart, 145-186.

MALLORY, J. P.; ADAMS, D. Q. (1997): Encyclopedia of IndoEuropean Culture, Londres-Chicago.

MELENA, J. L. (1985): Salama, Jálama y la epigrafía latina del antiguo corregimiento, Symbolae Ludovico Mitxelena septuagenario oblatae, Pamplona, 475-530.

MORENO, J. (1992): Martiago, Salamanca.

MOUSSY, C.; BUREAU, B. (1998): Moussyllanea: mélanges de linguistique et de littérature anciennes offerts à Claude Moussy, Lovaina-París.

OLIVARES, J. C. (2000): Los dioses soberanos y los ríos en la religión indígena de la Hispania indoeuropea, Gerion 18, 191-212.

OLIVARES, J. C. (2000-2001): Teónimos y fronteras étnicas: los lusitani, Lucentum 19-20, 245-256.

OLIVARES, J. C. (2001): Teónimos y pueblos indígenas hispanos: los vettones, Iberia 4, 57-69.

OLIVARES, J. C. (2002): Los Dioses de la Hispania Céltica, Madrid.
OLIVARES, J. C. (2017): Correcciones y nuevas interpretaciones sobre siete inscripciones votivas de Lusitania, Habis 48 , 171-185.

PALOMAR, M. (1957): La onomástica personal pre-latina de la Antigua Lusitania, Salamanca.

POKORNY, J. (1959): Indogermanisches Etymologisches Wörterbuch, Viena.

POWELL, T. G. E. (2005): Los Celtas, Madrid (1 $1^{\text {a }}$ ed., Londres, 1958).

PRÓSPER, B. (2002): Lenguas y religiones prerromanas del occidente de la Península ibérica, Salamanca.

PURPURA, P (2015): Cesare, il trionfo e l'elefante, Bulletino dell'Instituto di Diritto Romano «Vittorio Scialoja», 4 ser., 5, 225-246.

RÍO-MIRANDA, J. (2010): La Ciudad Romana de Cáparra. Municipium Flavium Caparense, Pamplona.

RÍO-MIRANDA, J.; IGLESIAS, M. G. (2007): Nuevas aportaciones a la Epigrafía y Arqueología romana de Cáceres. Inscripciones inéditas del Collado de Piedras Labradas, Jarilla (Cáceres), Ahigal (2a época) 29, 1-2 (digital).

ROSS, A. (1974): Pagan Celtic Britain, Londres.

SALINAS, M. (2013): Personal onomastics and local society in ancient Lusitania, Continental celtic word formation. The onomastic data (J.L. García Alonso, ed.), Salamanca, 17-36.

SAYANS, M. (1957): Artes y pueblos de la Alta Extremadura, Plasencia.

SOLÁ, J. N. (1967): Ensayo de antroponimia feno-púnica de la Hispania antigua, $R S O$ 42, 305-322.

SOLANA, J. M.; HERNÁNDEZ GUERRA, L. (2000): Religión y Sociedad en Época Romana en la Meseta Septentrional, Valladolid.

TOYNBEE, J. M. C. (1962): Art in Roman Britain, Londres.

TRANOY, A. (1981): La Galice romaine. Recherches sur le nordouest de la Péninsule Iberique dans l'antiquité, París.

UNTERMANN, J. M. (1965): Elementos de un atlas antroponímico de la Hispania antigua, Madrid.

VALLEJO, J. M. (2005): Antroponimia indígena de la Lusitania romana, Vitoria. 